\title{
Potential Factors of Mental Health Challenges During COVID-19 on the Young People in Dhaka, Bangladesh
}

\author{
Apu Chandra Das ${ }^{1 *}$, Aninda Roy ${ }^{2}$, Md Sakib Ibne Salam ${ }^{3}$ \\ ${ }^{1}$ University of Arkansas, Fayetteville, Arkansas, USA \\ ${ }^{2}$ Minnesota State University, Mankato, Minnesota, USA \\ ${ }^{3}$ University of Dhaka, Dhaka, Bangladesh \\ * Corresponding author email: acdas@uark.edu
}

Received: 17 June 2020 / Revised: 17 September 2020 / Accepted: 29 September 2020 / Published: 04 October 2020

\begin{abstract}
In this manuscript, we perform a Chi-square association test to find whether there is an association between the quarrelsome environment in the residence and mental health challenge and the corresponding p-value found to be 0.011 , which is statistically significant. In addition, we fit a logistic model to determine the factors influencing mental health challenges during the pandemic. The model shows that age, number of leaving home during the past 14 days, the effectiveness of work from home or online class, and feeling in response to COVID-19 are the significant factors affect the odds that a participant faces mental health challenges.
\end{abstract}

Keywords: COVID-19, Bangladesh, Quarrelsome environment, Mental health challenge

\section{Introduction}

With the outbreak of the novel coronavirus (2019-nCoV), the World Health Organization (WHO) declared the disease as a pandemic and an international public health emergency. It is a rapidly evolving and emerging situation. In less than nine months after the first emergence of the virus in December 2019, nearly thirty million people around the globe have been infected with 939,129 confirmed deaths. The researchers and scientists are working hard to understand better the genomic characteristics of this virus. As there are no vaccines or antiviral drugs approved for the disease, preventive measures like social-distancing, selfisolation, quarantine, international travel ban, and forced lockdown have been taken to control the spread of the virus. These are the most effective measures for flattening the curve of the infected cases and deaths, as several studies shows. For these reasons, billions of people worldwide are staying at home to minimize the transmission of the virus.

Dhaka, the capital city of Bangladesh, has the highest density of population with nearly 21 million people and struggling hard to combat against COVID-19. The preventive measures like lockdown, self-isolation, and social distancing are creating many challenges for the people. The mental health challenge is one of them. In this article, we try to find the significant factors associated with mental health challenges during this pandemic.

Psychological factors always become an important issue as people's reaction plays a vital role in spreading the disease and causing emotional distress and social disorder during any outbreak of infectious disease. The COVID-19 has been taken seriously because of its rapid increase in confirmed cases. The patients who have been infected intensely show severe respiratory symptoms and cardiovascular damage (Zheng et al., 2020). It does not only deteriorate the physical health condition but also causes mental anxiety. People are unaware of pandemic-related concerns like social distancing, quarantine, and isolation; social and economic crisis create sadness, fear, anger, frustration, and nervousness.

As a massively populated and lower-middle-income country, social distancing enforcement in Bangladesh appears robust while taking public commutes and many people living in the slums. The first confirmed case 
of COVID-19 appeared on March 8, but the expert speculated that the virus might have entered the country earlier but had not detected due to inadequate monitoring. In response to the emergence of the virus, Bangladesh admittedly reduced international flights, imposed thermal scanner checking, and shut down schools; however, offices maintained their regular schedules until March 26 (Anwar et al., 2020). On March 15, the airport authority banned all incoming and outgoing flights from Europe except the United Kingdom, and later, that was also stopped. In the meantime, more than 631 thousand people entered the country from different parts of the world from January 21 (Mamun, 2020), and specialists assumed these people make the country's pandemic situation more vulnerable.

During this viral epidemic, the mental health condition of medical and nursing staff is becoming very challenging. A study (Huang et al., 2020) has recently conducted on the medical staff of China, and 23\% of them found mentally anxious. In the Dhaka Medical College and Hospital, the largest government hospital in Bangladesh, four doctors were sent to home quarantine after they handled a person who later identified as having COVID-19. After that, fear and nervousness spread away among medical staff all over the country, and many of them refuse to provide healthcare services due to a lack of personal protective equipment (PPE) and other safety measures.

The majority of university students in Dhaka are from rural areas and earn their monthly expenses from private tutoring (PT) as part-time jobs are barely available. Because of the current pandemic, the Bangladesh government shut down all educational institutions as well as vacant student dormitories from March 26, and students immediately sent back to their homes. Self-employed students are passing a challenging time as they lost their PT opportunities. Losing these opportunities, students came from low-income families could not support their families nowadays, which is raising mental pressure and anxiety among them. Additionally, high-speed internet connection is not available in most rural areas, so it is not possible to continue academic activities online. Students who are living in town and cities spend most of their time on the internet due to maintaining social distancing. From our survey, we got $58.5 \%$ of respondents who agree that heavy internet usage affects their study as well as their work efficiency.

Moreover, during this pandemic time, most of the government and non-government organizations pause their activities and new job allocation procedures; that is the reason job-seeking individuals are in jeopardy, which would create uncertainty about their future. This situation upraises a big question about job safety among the present job seeker and future graduate students. Students who completed graduation 3/4 years ago but yet to get a job are undergoing a hard time as they might be exceeding their maximum age limit. In this situation, the stress and psychological problems of the current job holder, as well as job seekers, can be expected but not well addressed. There are several causes of traumatization, including high workload, lack of prospective devices, a non-effective infection control system, as well as surprisingly losing a job and staying $24 / 7$ days in the workstation. Government employees who work in the emergency department have to stay $24 / 7$ days in their workstation, which makes them separate from their family and friends. These are not generic scenarios of Bangladesh but seems to be a specific problem with the coronavirus outbreak. Due to maintaining social distance, most of the non-government employees are working from home (WFM), which might affect their efficiency in their regular working schedule (Joob and Wiwanitkit, 2020).

In severe cases, such mental issues guide people to commit suicidal actions. It is well established that $90 \%$ of suicide worldwide happens because of mental health challenges such as depression and fear (Mamun and Griffiths, 2020b). During this ongoing pandemic, a Bangladeshi guy committed suicide from the top roof of a building because of fear (Mamun and Griffiths, 2020a). The same scenarios have reported during the previous epidemic. For example, the suicide rate among older adults increased both during and after the SARS outbreak in Hong Kong (Cheung et al., 2008).

Bangladesh, a South Asian country, is densely populated and has more than 165 million population. Among them, one in five people (20\%) live below the poverty line; they earn their livelihood every day, and their average daily wage is below $\$ 5$. The poverty rate in a rural area, especially in north Bengal, is more extreme than the urban area (Khandker, 2012). In Bangladesh, the trend of COVID-19 cases is increasing, and due to the lockdown situation, the food supply is hampering severely. Most of the food items in Dhaka city 
Apu Chandra Das et al., Adv. J Social Sci.; Vol. 7, Issue 1, pp: 109-117, 2020

come from northern region and because of the lockdown all kinds of transposition are shut down that leads to price hiking which creates mental health challenges among the people. Since most farmers are not educated and adapted with new technology and facing labor shortage, their production has fallen into risk in terms of harvesting (Zabir et al., 2020). Approximately 35\% of the country people live below the poverty line, and suffer from food insecurity, own no assets, often uneducated (Hye et al., 1996). In urban areas, approximately $21 \%$ of people live below the poverty line, and they can often reach out to the basic needs compared to their rural counterparts. The people who earn the livelihood daily have lost their work opportunities due to the ongoing pandemic and currently leading a miserable life. Even those who work for renowned private companies are being dismissed from jobs as the companies are continuously losing revenues. Bangladesh Prime Minister declared 72750 crore BDT bailout for the RMG and other business sectors to minimize the economic impact of COVID-19 (Islam and Siddika, 2020).

\section{Materials and Methods}

Data has been collected through google docs platform from the currently located respondents in the Dhaka city of Bangladesh. We divided the whole population into three sub-groups based on their age, such as $<16$, 16-61, and 61+. As we collected data online and the people of age groups $<16$ and $61+$ barely use internet, we fixed the young people (16-61) as our study population. Another reason is that young people are suffering mostly compared to their counterparts as the colleges/universities are shut down, and job holders are losing their jobs. We excluded the individuals who do not have available internet connection and those who are not interested in the survey. We shared our survey link through social media mentioning the requirements of participating and also reached out to some known participants through messaging them personally to participate in the survey. The survey includes detail information on a participants' location within Dhaka city, his/her age, gender, marital status, occupation, the highest degree of education, monthly income, internet usage (before \& during) medium of receiving updates on COVID-19, feeling about social distancing, the effect of social distance on study or job efficiency, quarrelsome behavior in the residence, mental health challenges, hygiene situation, and daily hand washing. Our dependent variable is binary categorical; either the respondent is facing a mental health challenge or not. Respondents are mainly college/university students (59.4\%) and jobholders (25.1\%), and aged between 16-61 (86.6\% between 1628 age and $13.3 \%$ between 29-61) with the mean age of 25.13 . We collected a sample of 250 from the entire city, irrespective of religion, gender, race, and ethnicity. Our sample contains $63.3 \%$ male and $36.3 \%$ women; among them, $42.6 \%$ of the total respondents live in the off-campus but in the same city or town. Due to all educational institutions' sudden shutdown, only $6.4 \%$ of the respondents were staying on-campus housing. We also found that $42.8 \%$ of the participants who responded yes to the increasing quarrelsome environment in their residence, and $62.6 \%$ of respondents face different mental health challenges during this pandemic situation.

We fit a logistic regression model to estimate whether a respondent faces any mental health challenge due to the current outbreak. We also perform a Chi-square test to find an association between quarrelsome behavior in residence and the respondents' mental health condition. For most of the analysis, we used statistical software (R and SPSS). Table $1 \& 2$ show a short description of the relevant variables we used in this study.

Table 1: Variable Definitions (Continuous and Count) and Descriptive Statistics

\begin{tabular}{|l|l|c|c|}
\hline \multicolumn{1}{|c|}{ Variable } & \multicolumn{1}{|c|}{ Definition } & Mean & Standard Deviation \\
\hline Age & Individual's age in years & 25.13 & 5.72 \\
Internet usage (before) & Daily internet use (before) & 4.72 & 3.41 \\
Internet usage (during) & Daily internet use (during) & 7.42 & 4.28 \\
Hand washing & Daily hand washing & 10.15 & 7.68 \\
Leaving home & Leaving home during last 14 days & 5.25 & 10.12 \\
\hline
\end{tabular}


Table 2: Variable Definitions (Categorical) and Frequency

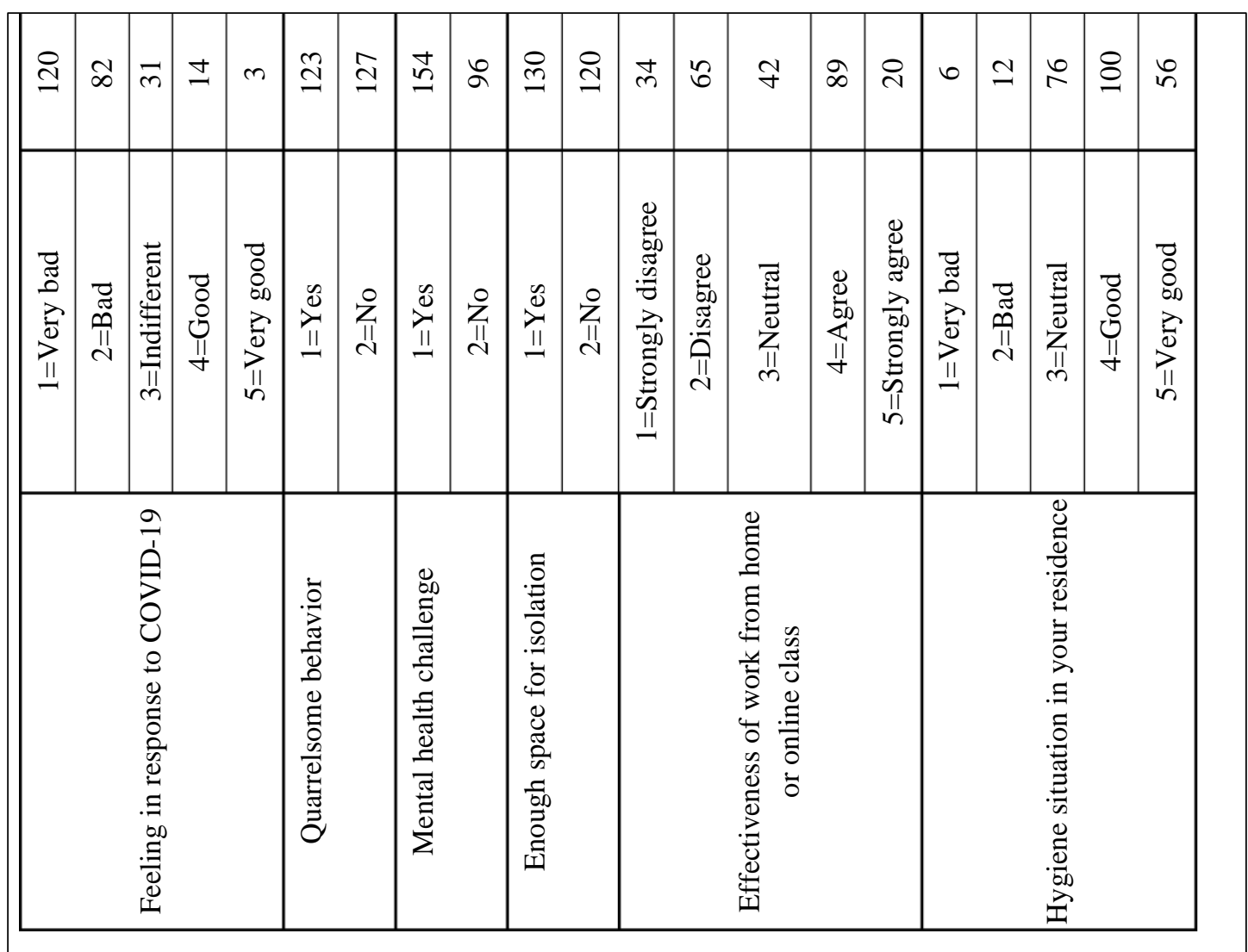

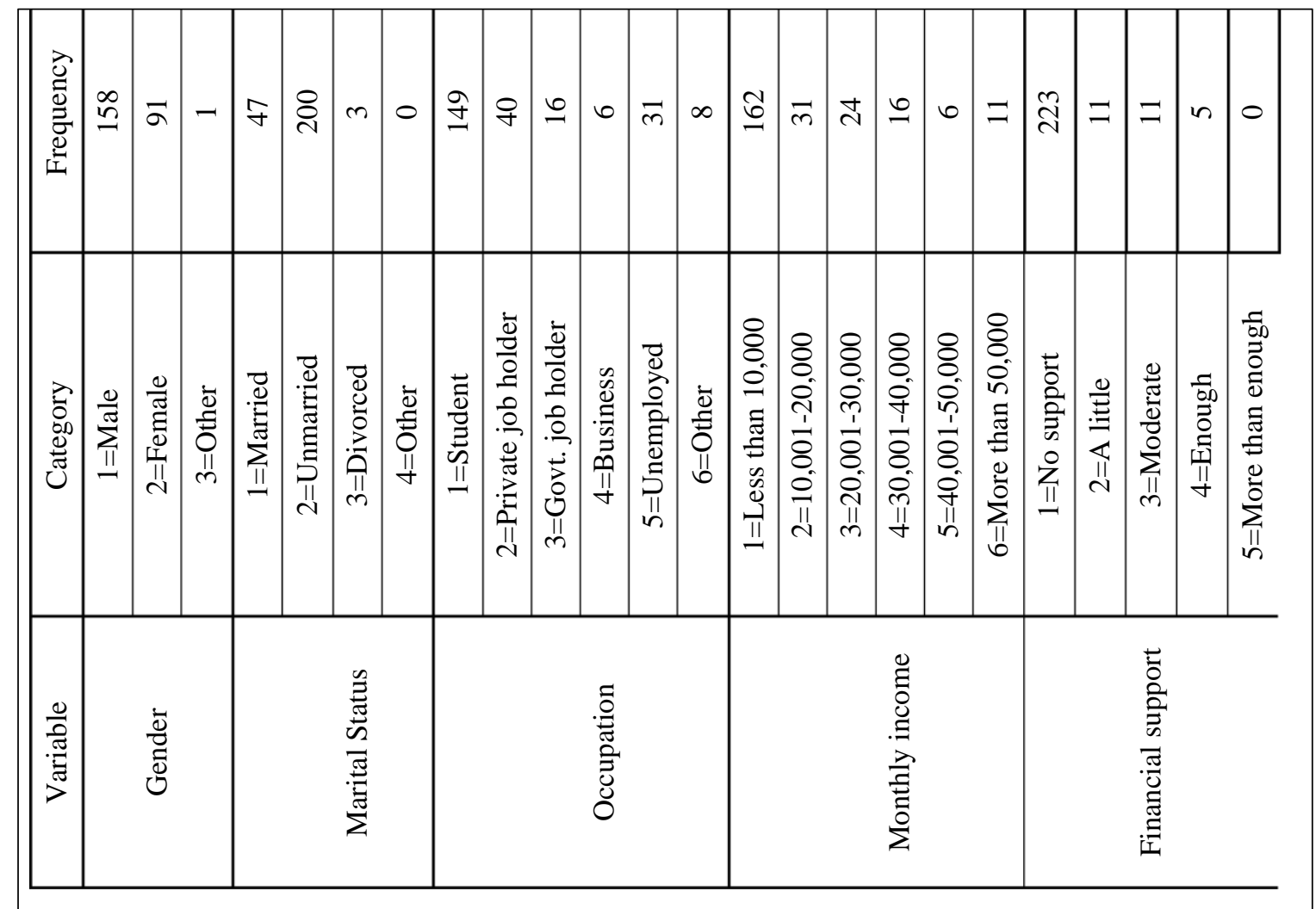




\section{Results and Discussion}

\subsection{Basic Trends}

First COVID-19 case has appeared in Bangladesh on March 8, 2020, and after that government started taking precautions for flattening the curve of infected cases and deaths. They announced national vacation from March 26, 2020, even educational institutions, markets, cinema halls were shut down before that and banned all kinds of domestic and international flights. Then the national vacation has been extended several times until June 1. People are allowed to go out only in emergencies. Nevertheless, people are stepping out sporadically and do not maintain social distancing, which is responsible for the exponential increase of the infected cases. Dhaka, the capital of Bangladesh, is a densely populated city, and more than 21 million people live there (World Population Review, 2020). According to IEDCR, more than 50\% of cases found in the Dhaka division, and among them, $70 \%$ are from Dhaka city. Male people are more vulnerable than their female counterparts, and as of September 13, 2020, the ratio of the percentage of being infected is $71: 29$, but, surprisingly, the death ratio is $77: 23$. Age group 21 to 30 is at high risk of being infected, but, astonishingly, the death rate is the highest (39\%) among the people who are above 60 (IEDCR, 2020).
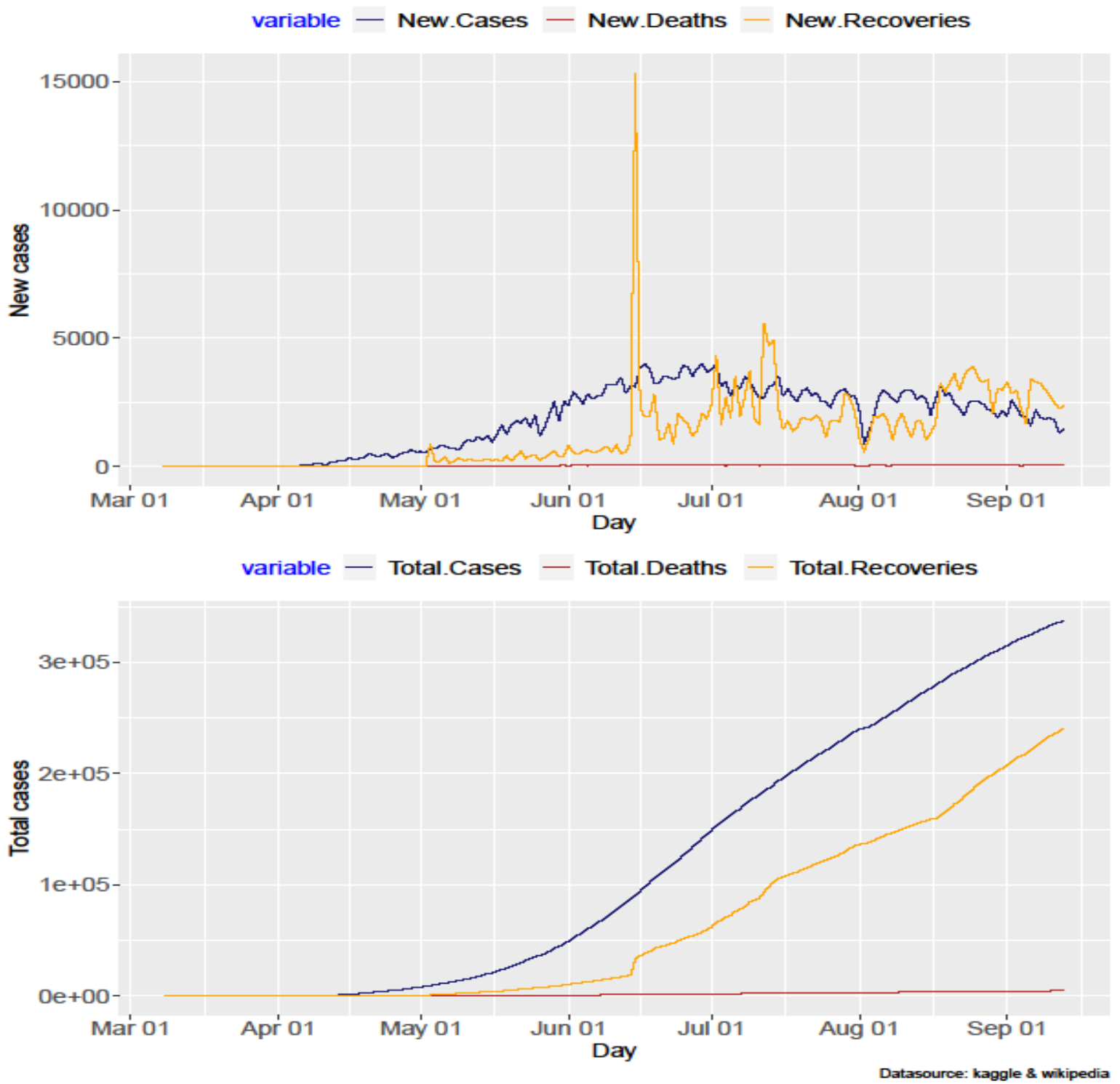

Figure 1: Current situation regarding COVID-19 in Bangladesh (September 13, 2020). The top plot shows daily new cases, deaths, and recoveries; and the bottom one shows total cases, deaths, and recoveries. 
In figure 1, the number of new cases, total cases, new deaths, total deaths, new recoveries, and total recoveries have been shown. The first plot shows that the daily new cases were increasing exponentially until July but started decreasing after that except some drops, while the line of regular death cases is growing uniformly throughout the entire period, which is very unusual. In the middle of June, surprisingly, approximately 15,500 people have been recovered in one day, whereas the number was below a thousand before June. After the peak, the number fell significantly, showing some ups and downs. The second plot tells the total confirmed cases line is increasing exponentially, and the total recovery line is moving forward parallelly. The entire recovery line was smooth until May, but more people started recovering from the second day of May. So, Bangladesh entered a critical situation from May, though the first case had appeared on March 8.

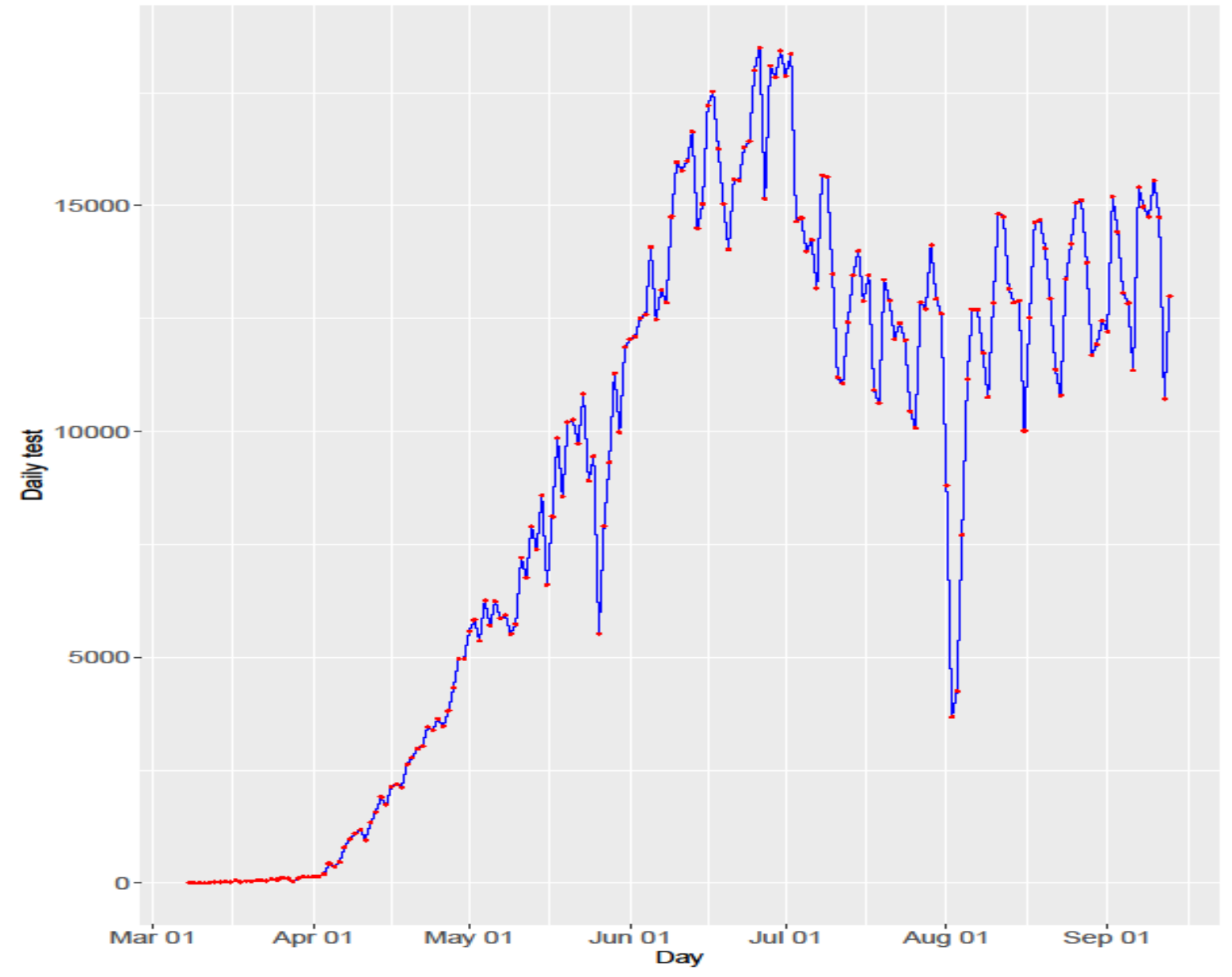

Figure 2: Daily no. of tests

From figure 2, we can see that the number of daily tests was deficient throughout March and started increasing from the first week of April. Moreover, the daily number of tests remained below 100 before April. After the identification of the first case of COVID-19, it took four weeks to raise the frequency of testing in the country significantly. There is a sudden drop on August 2 because of the Eid-ul-Adha, which is a national holiday. According to the Worldometer, Bangladesh is the second-lowest country in terms of the daily number of tests in Asia. Moreover, most of the hospitals do not have enough personal protective equipment (PPE) and diagnostic testing capacity. Fear, anxiety about this virus have been rising significantly among the general people as well as the hospital staff, which restricts the testing procedure. As a result, many doctors and health staff tested positive for COVID-19 and were sent to quarantine. As of September 13 , the number of the total sample tested is $1,731,385$, and 337,750 cases found to be positive. Though it seems the number of confirmed cases is still lower in Bangladesh, this is not the actual scenario. This number will increase alarmingly with the increase in daily tests. 
Apu Chandra Das et al., Adv. J Social Sci.; Vol. 7, Issue 1, pp: 109-117, 2020

\subsection{Association Between Quarrelsome Environment and Mental Health Challenge}

As both variables are binary categorical, we use the Chi-square test of independence to assess whether there is a significant association between them. The hypotheses for this test are as follows:

$\mathrm{H}_{0}$ : There is no association between quarrelsome environment and mental health challenge $\mathrm{H}_{1}$ : There is an association between quarrelsome environment and mental health challenge The following test statistic has been used to conduct the test.

$$
\chi^{2}=\sum \frac{\left(f_{i j}-e_{i j}\right)^{2}}{e_{i j}}
$$

where $\mathrm{f}_{\mathrm{ij}}$ and $\mathrm{e}_{\mathrm{ij}}$ are the observed and expected frequency count corresponding to the ith category of $\mathrm{X}$ and jth category of $\mathrm{Y}$, respectively.

We found $\chi^{2}=6.408$ with $\mathrm{df}=1$ and $\mathrm{p}$-value $=0.01136$, which warrants that there is an association between the two variables at a $5 \%$ level of significance. So, a change in the distribution of quarrelsome environment influences the distribution of mental health challenges.

\subsection{Factors Influencing Mental Health Challenge During COVID-19}

We use the binary logistic model to determine how factors impact the probability or odds ratio that an individual will face mental health challenges during the COVID-19 pandemic. An ordinary least square (OLS) model is not an ideal choice because the response variable 'Mental health challenge' is a binary categorical variable and has two categories $(1=\mathrm{Yes}, 2=\mathrm{No})$. We put a set of 5 covariates in the model, some of them are continuous, and some are categorical. Continuous predictors are directly used in the model, while we create dummy variables for categorical predictors and consider the first category of each variable as a reference or baseline category.

Table 3 shows the summary statistics of the above fitted logistic regression model. We report estimated coefficients, exponential of the coefficients, their standard errors, z-values, and p-values correspondingly. We found Age, Leaving Home, Quarrelsome Environment, working from home (WFH) or online classes (OC) effective, and Feeling COVID19 are significant determinants of estimating the probability of mental health challenge. The exponent of the estimated coefficients delineates the factor by which odds increase

Table 3: Logistic Regression Model for Mental Health Challenge

\begin{tabular}{|l|c|c|c|c|c|}
\hline \multicolumn{1}{|c|}{ Variable } & Estimate & Exp (Estimate) & S.E. & z value & $\operatorname{Pr}(>|\mathrm{z}|)$ \\
\hline Intercept & 0.693 & 2.000 & 0.856 & 0.810 & 0.418 \\
Age & -0.088 & 0.915 & 0.030 & -2.926 & $0.003^{* *}$ \\
Leaving Home & 0.038 & 1.039 & 0.016 & 2.379 & $0.017^{*}$ \\
Quarrelsome Environment (No) & -0.740 & 0.477 & 0.294 & -2.518 & $0.012^{*}$ \\
WFH or OC effective (Disagree) & 0.446 & 1.562 & 0.520 & 0.859 & 0.391 \\
WFH or OC effective (Neutral) & 1.434 & 4.198 & 0.550 & 2.606 & $0.009^{*}$ \\
WFH or OC effective (Agree) & 0.615 & 1.849 & 0.498 & 1.235 & 0.217 \\
WFH or OC effective (Strongly agree) & 1.206 & 3.341 & 0.642 & 1.878 & 0.060. \\
Feeling COVID19 (Bad) & 0.890 & 2.435 & 0.323 & 2.755 & $0.006^{* *}$ \\
Feeling COVID19 (Indifferent) & 1.169 & 3.219 & 0.440 & 2.655 & $0.008^{* *}$ \\
Feeling COVID19 (Good) & -0.004 & 0.997 & 0.652 & -0.005 & 0.995 \\
Feeling COVID19 (Very good) & 2.688 & 14.709 & 1.363 & 1.972 & $0.049 *$ \\
\hline
\end{tabular}

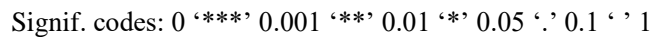

Null deviance: 332.99 , Residual deviance: 293.75 , AIC: 317.75 
if the predictor increases by one unit. So, if age increases by one year, the odds ratio of having mental health challenge rises by a factor of 0.915 . Similarly, leaving home during the past 14 days also has a positive influence on the odds of mental health challenge, which is $3.9 \%$. The odds of facing mental health challenges are lower for the individuals who do not have a quarrelsome environment in their residence by a factor of 0.477 , or about $52 \%$. Again, the participants who think working from home or virtual class is neither helpful nor annoying are having mental health challenges relative to the people who do not feel comfortable with the online class or work from home by a factor of 4.198. Finally, the odds of having mental health challenges are higher by a factor of 2.435 and 3.219 for the respondents who are feeling bad and indifferent, respectively, in response to COVID-19 than those who feel very bad.

We choose a model with a minimum AIC value. Though the lowest AIC value was 310, that was a bit complicated model with lots of predictors. So, we choose a simpler model with fewer predictors, but a bit higher AIC value. In the outcome variable of the actual data, 154 individuals are facing mental health challenges, and the other 96 people do not have that problem. To find the accuracy of the fitted model, we separate the actual dataset into training and testing sets; and the training set consists of $75 \%$ of the observations. First, we fit a logistic model on the training data, then predict the outcome of the testing data.

Table 4: Confusion or Classification Matrix

\begin{tabular}{|c|c|c|}
\hline $\mathbf{n = 6 2}$ & Predicted Yes & Predicted No \\
\hline Actual Yes & 33 & 5 \\
\hline Actual No & 13 & 11 \\
\hline
\end{tabular}

Table 4 shows actual count vs predicted count of each category. Out of 62 test responses, our model correctly identifies 33 who have mental health challenges, and 11 who do not have any mental health challenges. Prediction accuracy can be computed from the table, which is $71 \%$ for the fitted model.

\section{Conclusions}

In this study, we show that a considerable percentage of students and early professionals of Bangladesh is dealing with the loss of efficiency of their healthy working life, anxiety about an uncertain future career. Furthermore, financial insecurities, becoming dependent mostly on social media making their daily life miserable. The mental health challenges they are going through in this pandemic time could be a severe issue for the future academic and professional breakdown. So, to overcome this state, the government should create a new health care facility such as online counselling for students, which would relieve them from their mental challenges. They also can create many online learning platforms where students and professionals can gather knowledge from the home environment and also use what they have already learned for their future career growth. We would suggest the government to provide high-speed internet throughout the country. Additionally, mobile operators should make their network stronger and announce new internet packages at an affordable rate for everyone. It will help the students and job holders to continue their online class and work from home efficiently, and, at the same time, it is also helpful to release their mental anxiety, fear, nervousness, and loneliness. We would also suggest carrying out a rigorous epidemiological study to assess the level of fear, helplessness, and mental health of the people and take proper steps such as online counselling and telemedicine service.

\section{Declarations}

\subsection{Study Limitations}

As the survey was conducted through social media, we were unable to reach out to the people of age categories below 16 and above 61. We collected data mainly from the young people, ranges from 16 to 61 . 


\subsection{Acknowledgements}

We would like to express our special thanks of gratitude to all our teachers whose unbelievable guidance helps us to run our research study and we came to know about so many things. We would also like to thank all our respondents who gave their valuable time to complete the survey by providing invaluable information. This work was carried out in collaboration and hard work of all authors. Finally, any attempt at any level cannot be satisfactorily completed without the support of our parents and friends. We are thankful to them.

\subsection{Survey Duration}

This survey has been taken place from May 12, 2020 through May 17, 2020 when the COVID-19 confirmed cases was increasing significantly.

\subsection{Informed Consent}

Consent was sought at the beginning of the survey from the participants. We included only the individuals who had wanted to take part in the survey.

\subsection{Competing Interests}

The authors declared that there is no conflict of interest in this manuscript publication.

\section{How to Cite this Article:}

Das, A. C., Roy, A., \& Salam, M. S. I. (2020). Potential Factors of Mental Health Challenges During COVID-19 on the Young People in Dhaka, Bangladesh. Advanced Journal of Social Science, 7 (1), 109-117. https://doi.org/10.21467/ajss.7.1.109-117

\section{References}

[1] Anwar, S., Nasrullah, M., and Hosen, M. (2020). Covid-19 and Bangladesh: Challenges and how to address them. front. Public Health, $8: 154$.

[2] Cheung, Y., Chau, P. H., and Yip, P. S. (2008). A revisit on older adults suicides and severe acute respiratory syndrome (sars) epidemic in hong kong. International Journal of Geriatric Psychiatry: A journal of the psychiatry of late life and allied sciences, 23(12):12311238 .

[3] Huang, J., Han, M., Luo, T., Ren, A., and Zhou, X. (2020). Mental health survey of 230 medical staff in a tertiary infectious disease hospital for covid-19. Zhonghua lao dong wei sheng zhi ye bing za zhi=Zhonghua laodong weisheng zhiyebing zazhi= Chinese journal of industrial hygiene and occupational diseases, 38:E001-E001.

[4] Hye, H. A. et al. (1996). Below the line: rural poverty in Bangladesh. University Press Limited.

[5] Islam, M. D. and Siddika, A. (2020). Covid-19 and Bangladesh: A study of the public perception on the measures taken by the government.

[6] Joob, B. and Wiwanitkit, V. (2020). Traumatization in medical staff helping with covid-19 control. Brain, Behavior, and Immunity.

[7] Khandker, S. R. (2012). Seasonality of income and poverty in Bangladesh. Journal of Development Economics, 97(2):244-256.

[8] Mamun, M. A. (2020). Govt Now Scrambles for Testing Kits, PPE. (2020). Available online at. https://www.thedailystar.net/frontpage/news/govt-now-scrambles-testing-kits-ppe-1882633.

[9] Mamun, M. A. and Griffiths, M. D. (2020a). First covid-19 suicide case in Bangladesh due to fear of covid-19 and xenophobia: Possible suicide prevention strategies. Asian journal of psychiatry, 51:102073.

[10] Mamun, M. A. and Griffiths, M. D. (2020b). A rare case of Bangladeshi student suicide by gunshot due to unusual multiple causalities. Asian journal of psychiatry, 49:101951.

[11] Zabir, A. A., Mahmud, A., Islam, M. A., Antor, S. C., Yasmin, F., and Dasgupta, A. (2020). Covid-19 and food supply in Bangladesh: A review. Available at SSRN 3595967.

[12] Zheng, Y.-Y., Ma, Y.-T., Zhang, J.-Y., and Xie, X. (2020). Covid-19 and the cardiovascular system. Nature Reviews Cardiology, 17(5):259-260.

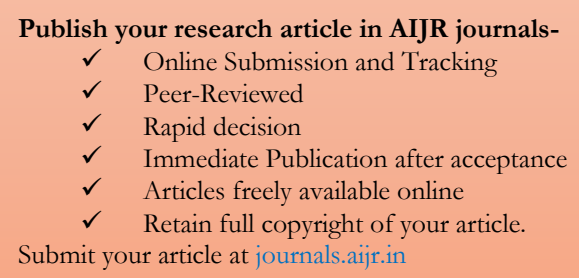

Publish your books with AIJR publisher-

$\checkmark \quad$ Publish with ISBN and DOI.

$\checkmark$ Publish Thesis/Dissertation as Monograph.

$\checkmark$ Publish Book Monograph.

$\checkmark \quad$ Publish Edited Volume/ Book.

$\checkmark \quad$ Publish Conference Proceedings

$\checkmark \quad$ Retain full copyright of your books

Submit your manuscript at books.aijr.org 